\title{
Determination of the Physical Properties of Room Temperature Ionic Liquids Using a Love Wave Device
}

\author{
F. Fouzia Ouali, ${ }^{,+\dagger}$ Nicola Doy, ${ }^{\dagger}$ Glen McHale, ${ }^{\dagger}$ Christopher Hardacre, ${ }^{\ddagger}$ Rile Ge, ${ }^{\ddagger}$ Ray W. K. Allen, ${ }^{\S}$ \\ Jordan M. MacInnes, ${ }^{\S}$ and Michael I. Newton ${ }^{\dagger}$ \\ ${ }^{\dagger}$ School of Science \& Technology, Nottingham Trent University, Clifton Lane, Nottingham NG11 8NS, U.K. \\ ${ }^{\ddagger}$ QUILL Centre, School of Chemistry \& Chemical Engineering, Queen’s University, Belfast, Belfast BT9 5AG, U.K. \\ ${ }^{\S}$ Department of Chemical \& Process Engineering, University of Sheffield, Newcastle Street, Sheffield S1 3JD, U.K.
}

\begin{abstract}
In this work, we have shown that a $100 \mathrm{MHz}$ Love wave device can be used to determine whether room temperature ionic liquids (RTILs) are Newtonian fluids and have developed a technique that allows the determination of the density-viscosity product, $\rho \eta$, of a Newtonian RTIL. In addition, a test for a Newtonian response was established by relating the phase change to insertion loss change. Five concentrations of a water-miscible RTIL and seven pure RTILs were measured. The changes in phase and insertion loss were found to vary linearly with the square root of the density-viscosity product for values up to $(\rho \eta)^{1 / 2} \sim 10 \mathrm{~kg} \mathrm{~m}^{-2} \mathrm{~s}^{-1 / 2}$. The square root of the density-viscosity product was deduced from the changes in either phase or insertion loss using glycerol as a calibration liquid. In both cases, the deduced values of $\rho \eta$ agree well with those measured using viscosity and density meters. Miniaturization of the device, beyond that achievable with the lower-frequency quartz crystal


microbalance approach, to measure smaller volumes is possible. The ability to fabricate Love wave and other surface acoustic wave sensors using planar metallization technologies gives potential for future integration into lab-on-a-chip analytical systems for characterizing ionic liquids.
\end{abstract}

\begin{abstract}
A s their name indicates, room temperature ionic liquids (RTILs) are liquids that are composed entirely of ions and that remain liquids at room temperature. They are generally very stable over a large temperature range, nonflammable, and have low volatility and are therefore rapidly emerging as alternative environmentally friendly solvents. ${ }^{1-3}$ Their applications have been reported in a wide range of areas, including organic synthesis, catalysis, electrochemistry, ${ }^{4}$ liquid crystal, ${ }^{5}$ and separation technologies. ${ }^{6,7}$ With over a million simple ionic liquids available, scientists and engineers are presented with numerous opportunities to design ionic liquids with specific properties for different applications but also with challenges to develop methods to characterize them to optimize their properties. Although with increasing utilization, the cost of some ionic liquids is decreasing, ionic liquids are, in general, relatively expensive, and new ionic liquids require synthetic routes to be developed. Currently, full characterization of the physical properties of such ionic liquids requires significant volumes of material to be synthesized before it is known whether they are useful for the process to be developed. Therefore, to reduce the synthetic burden and the cost, robust and high-throughput analytical techniques that require minimal volumes of liquids for characterization are desirable.

High-frequency acoustic wave devices are widely used in telecommunications but also provide a surface oscillation that can be used to probe or sense materials with which they come
\end{abstract}

into contact. In a Rayleigh-type surface acoustic wave, the oscillation includes an out-of-plane component, and this prevents their use with most liquids because on contact with the liquid, the wave's component of displacement normal to the surface generates a compressional wave into the liquid, giving rise to significant attenuation of the surface wave. However, acoustic wave sensors, using a shear-wave polarization with a particle displacement in the plane of the device surface, do not generate compressional waves and have been successful in liquid sensing applications. ${ }^{8-10}$ Device types include the quartz crystal microbalance (QCM), which uses a thickness shear mode operation, and the surface acoustic wave device (SAW), which uses a planar fabricated set of interdigital transducers (IDTs) to excite the wave. Both types of sensors operate by creating a highfrequency shear wave that entrains the liquid present on the surface and causes a change in the wave velocity and amplitude. Recently, a QCM operating at a fundamental frequency of $5 \mathrm{MHz}$ and its harmonics was successfully used to study the Newtonian response of RTILs by measuring the shift in the resonant frequency of the device and its bandwidth after the liquid is introduced. ${ }^{11}$ This showed that the density-viscosity product of a liquid can be determined from only $40 \mu \mathrm{L}$ of liquid

Received: May 25, 2011

Accepted: July 25, 2011

Published: July 25, 2011 
without the need for a calibration liquid. The viscosity could then be deduced if the density of the liquid is known. The volume was reduced to $30 \mu \mathrm{L}$ when a $\mathrm{QCM}$, operating at $8 \mathrm{MHz}$, was incorporated on a glass microfluidic chip. ${ }^{12}$

In this article, we extend the work presented in references 11 and 12 to much higher frequencies $(\sim 100 \mathrm{MHz})$ using a shear horizontal polarized surface acoustic wave (SH-SAW), which has the advantage of increased sensitivity at higher operating frequencies. Equivalent increases in the operating frequency of a QCM are technically difficult because they involve thinning the crystal substrate, thus making it fragile; a particular problem when operated as part of a microfluidic flow cell. In the SH-SAW case, the operating frequency is determined by the period of surface fabricated interdigital transducers and so does not require a thin substrate. Moreover, the planar fabrication technology of the SH-SAW has greater potential for integration into microfluidic chips. To enhance the sensitivity beyond that obtained with a simple SH-SAW, a Love wave configuration was used, in which the substrate is overlaid with a guiding layer possessed of a smaller shear velocity than that of the substrate. This ensures the wave remains in the vicinity of the surface of the device and uses the dispersive nature of the wave caused by the guiding layer to enable a small interaction with a liquid to give a large, measurable change in the velocity and amplitude of the wave. 13,14

\section{THEORY}

Liquids present on the surface of a SAW device change both velocity (and hence, phase, $\Delta \Phi$ ) and amplitude of the wave, $\Delta A$. For viscous (Newtonian) liquids, these changes, with respect to air are proportional to the square root of the density-viscosity product of the liquid, $(\rho \eta)^{1 / 2} \cdot{ }^{15,16}$ The changes can be expressed as ${ }^{16,17}$

$$
\begin{aligned}
& \Delta \Phi(\mathrm{deg})=c L_{\mathrm{s}} k_{0} \frac{360}{2 \pi} \sqrt{\frac{\omega \rho \eta}{2}} \text { and } \\
& \Delta A(\mathrm{~dB})=20 \log (\mathrm{e}) c L_{\mathrm{s}} k_{0} \sqrt{\frac{\omega \rho \eta}{2}}
\end{aligned}
$$

where $c$ is dependent on device parameters and geometry; $L_{\mathrm{s}}$ is the length of the propagation path of the wave; $k_{0}$ is the wavevector; $\omega$ is the angular frequency; and $\rho$ and $\eta$ are the density and viscosity of the liquid, respectively. Measuring changes in phase and amplitude for a SAW are the equivalent of measuring changes in frequency, $\Delta f$, and bandwidth, $\Delta B$, for a QCM device; eq 1 is the analogue of the Kanazawa and Gordon equation. ${ }^{18}$ If the changes are measured with respect to another liquid, then the corresponding changes for the liquid need to be subtracted from the signals in eq 1.

The ratio of phase change to amplitude change at a given frequency can be evaluated from eq 1 as

$$
\frac{\Delta \Phi(\mathrm{deg})}{\Delta A(\mathrm{~dB})}=\frac{360}{40 \pi \log (\mathrm{e})} \cong 6.60 \mathrm{deg} \mathrm{dB}^{-1}
$$

Hence, a linear correlation between the two quantities is expected for Newtonian liquids with $\Delta \Phi \sim 6.60 \Delta A$. This provides a simple experimental test for determining whether a RTIL is Newtonian, in much the same manner as the frequency change-bandwidth change correlation, $\Delta f=-\Delta B / 2$, previously reported for the response of a QCM to RTILs. ${ }^{11}$

At a given frequency, the relationships in eq 1 remain linear for liquids with viscosities up a critical value $\eta_{\mathrm{c}}=\mu / \omega,{ }^{15,19-21}$ where $\mu$ is the high frequency shear modulus, and hence, there is a frequency-dependent critical value of the density-viscosity product $\left(\rho \eta_{c}\right)^{1 / 2} \propto \omega^{-1 / 2}$. Liquids with viscosities larger than $\eta_{\mathrm{c}}$ do not have enough time to respond to shear deformation over one period of oscillation of the wave, so energy cannot be lost through viscous dissipation, and as a result, they behave like solids (Maxwellian). ${ }^{15-17,22,23}$ For these liquids, the changes in phase and loss both deviate from the linear relationship (eq 1). The loss eventually saturates, ${ }^{15}$ and the phase change decreases with increasing $(\rho \eta)^{1 / 2} \cdot 17,24$ The saturation value for amplitude loss can be expressed as ${ }^{15}$

$$
\Delta A_{\mathrm{sat}}(\mathrm{dB})=c 20 \log (\mathrm{e}) L_{\mathrm{s}} k_{0} \sqrt{\frac{\rho \mu}{2}}
$$

It is, therefore, possible to determine from phase and amplitude measurements whether a liquid is Newtonian at a given frequency of interrogation by verifying the validity of eq 2 . If the liquid is Newtonian, estimates of the density-viscosity product can be extracted using either the phase change or the amplitude change via eq 1 , and from knowledge of the density, the viscosity can be deduced.

\section{EXPERIMENTAL SECTION}

Surface acoustic wave devices were fabricated to operate at $\sim 100 \mathrm{MHz}$ on ST-X cut quartz using a standard photolithography process. ST-quartz is known to support a Rayleigh wave parallel to the $x$-axis and a surface-skimming bulk wave (SSBW) perpendicular to the $x$-axis, which with the addition of an overlayer film with a lower speed than the substrate can result in Love wave propagation. ${ }^{25,26}$ Two $\mathrm{Ti}-\mathrm{Au}$ IDTs were fabricated from a $100 \mathrm{~nm}$ sputtered gold layer over a $10 \mathrm{~nm}$ thick titanium adhesive layer. Each IDT consisted of 88 finger pairs with a period $\lambda=25.5 \mu \mathrm{m}$, finger length of $2.153 \mathrm{~mm}$ long and aperture of $2 \mathrm{~mm}$. The IDTs were $7.65 \mathrm{~mm}$ apart, giving a sensitive area in the SAW propagation path of $\sim 15 \mathrm{~mm}^{2}$.

To reduce the electroacoustic effects associated with the interaction of the ionic liquids and the electric field of uncoated devices, a metallic pad was deposited on the propagation path between the IDTS to short the electric field and, hence, screen out electroacoustic effects. ${ }^{24,27}$ The metallic pad consisted of a $100 \mathrm{~nm}$ sputtered Au over a 10-nm-thick Ti adhesive layer. This gold area was designed to be large enough to cover the area in contact with the sample liquid. The device was then converted into operating in a Love wave mode by RF sputter-coating a silicon dioxide $\left(\mathrm{SiO}_{2}\right)$ guiding layer over the entire surface, leaving only the IDT connecting pads exposed. $\mathrm{SiO}_{2}$ was chosen because it is chemically robust ${ }^{28}$ and should withstand long exposure to RTILs. The samples were placed in a custom flow cell designed to be chemically resistant to RTILs. The SAW device was clamped into a brass holder that contained spring pin contacts to connect to the IDT pads. A PTFE T-piece insert was made to slide into the brass holder, and a PTFE encapsulated Viton O-ring seal was placed between the T-piece and the SAW device with these pieces clamped tight to form a seal. PFA tubing was used to connect the PTFE to a $5 \mathrm{~mL}$ syringe, from which the liquids were gently pushed through the cell. A total sample volume of $1.5 \mathrm{~mL}$ was used, although only $\sim 80 \mu \mathrm{L}$ was actually required in the SAW propagation path; reducing the height of the O-ring could further reduce significantly the volume required. The measurements were carried out in a glovebag under argon atmosphere to reduce the absorption of moisture by the RTILs. 
Table 1. Concentrations (\% v/v) of Water-Glycerol and Ionic Liquids Used and Their Corresponding Viscometer and Densitometer Measured Squared Root Density-Viscosity Product

\begin{tabular}{|c|c|c|c|}
\hline liquid & $\begin{array}{c}(\rho \eta)^{1 / 2}\left(\mathrm{~kg} \mathrm{~m}^{-2} \mathrm{~s}^{-1 / 2}\right) \\
\left(\text { at } 25^{\circ} \mathrm{C}\right)\end{array}$ & $\begin{array}{l}\text { [halide] } \\
\text { (ppm) }\end{array}$ & $\begin{array}{c}{[\mathrm{Ag}]} \\
(\text { wt \%) }\end{array}$ \\
\hline water & 0.99 & & \\
\hline water-glycerol $45 \%$ & 2.15 & & \\
\hline water-glycerol $55 \%$ & 2.78 & & \\
\hline water-glycerol $60 \%$ & 3.20 & & \\
\hline water-glycerol $65 \%$ & 3.73 & & \\
\hline water-glycerol $70 \%$ & 4.65 & & \\
\hline water-glycerol $85 \%$ & 9.13 & & \\
\hline water-glycerol 90\% & 12.76 & & \\
\hline$\left[\mathrm{C}_{2} \mathrm{mim}\right]\left[\mathrm{EtSO}_{4}\right] 25 \%$ & 1.14 & & \\
\hline$\left[\mathrm{C}_{2} \mathrm{mim}\right]\left[\mathrm{EtSO}_{4}\right] 50 \%$ & 2.08 & & \\
\hline$\left[\mathrm{C}_{2} \mathrm{mim}\right]\left[\mathrm{EtSO}_{4}\right] 75 \%$ & 4.80 & & \\
\hline$\left[\mathrm{C}_{2} \mathrm{mim}\right]\left[\mathrm{EtSO}_{4}\right] 90 \%$ & 5.23 & & \\
\hline$\left[\mathrm{C}_{2} \mathrm{mim}\right]\left[\mathrm{EtSO}_{4}\right] 100 \%$ & 9.07 & $d$ & \\
\hline$\left[\mathrm{C}_{4} \mathrm{mim}\right]\left[\mathrm{MeSO}_{4}\right] 100 \%$ & 10.21 & $<5^{b}$ & \\
\hline$\left[\mathrm{C}_{4} \mathrm{mpyrr}\right][\mathrm{DCA}] 100 \%$ & 5.78 & $<1790^{b}$ & \\
\hline$\left[\mathrm{C}_{2} \mathrm{mim}\right][\mathrm{SCN}] 100 \%$ & 4.94 & $<5^{b}$ & \\
\hline$\left[\mathrm{C}_{4} \mathrm{mim}\right][\mathrm{TFA}] 100 \%$ & $9.42^{a}$ & $<1.5^{c}$ & 1.4 \\
\hline$\left[\mathrm{P}_{6,6,6,6,14}\right]\left[\mathrm{NTf}_{2}\right] 100 \%$ & 17.04 & $<50^{b}$ & \\
\hline$\left[\mathrm{C}_{10} \mathrm{mim}\right]\left[\mathrm{NTf}_{2}\right] 100 \%$ & 13.87 & $<5^{c}$ & \\
\hline
\end{tabular}

${ }^{a}$ This value for $\left[\mathrm{C}_{4} \mathrm{mim}\right][\mathrm{TFA}]$ corrects the previously published value of $21.1 \mathrm{~kg} \mathrm{~m}^{-2} \mathrm{~s}^{-1 / 2}$ in ref $11 .{ }^{b} \mathrm{Cl}^{-}$measured using IC. ${ }^{c} \mathrm{Br}$ measured using IC. ${ }^{d}$ Halogen-free sample.

Two types of liquids were used: aqueous glycerol solutions of different concentrations (up to 90\%) as reference liquids and RTILs. Measurements on five concentrations of the water miscible RTIL, $\left[\mathrm{C}_{2} \mathrm{mim}\right]\left[\mathrm{EtSO}_{4}\right]$, and an additional seven pure RTILs were investigated (Table 1). Measurements of the viscosity and density were made using a Brookfield DVII+ programmable viscometer and an Anton Parr DMA 4500 oscillating tube density meter. These techniques require 1.5 and $0.5 \mathrm{~mL}$ of liquid respectively. The temperature for both density and viscosity measurements was set to $25^{\circ} \mathrm{C}$ via a water bath.

1-Butyl-1-methylpyrrolidinium dicyanamide ([ $\left.\left.\mathrm{C}_{4} \mathrm{mpyrr}\right][\mathrm{DCA}]\right)$, 1-ethyl-3-methylimidazolium thiocyanate $\left(\left[\mathrm{C}_{2} \mathrm{mim}\right][\mathrm{SCN}]\right)$, and 1-butyl-3-methylimidazolium methylsulfate $\left[\mathrm{C}_{4} \mathrm{mim}\right][\mathrm{MeSO} 4]$ were obtained from Merck (98\%). 1-Ethyl-3-methylimidazolium ethyl sulfate $\left(\left[\mathrm{C}_{2} \mathrm{mim}\right]\left[\mathrm{EtSO}_{4}\right]\right)$ was prepared by reacting 1-methylimidazole with diethyl sulfate according to previously reported procedures. ${ }^{29}$ 1-Butyl-3-methylimidazolium trifluoroacetate $\left(\left[\mathrm{C}_{4} \mathrm{mim}\right][\mathrm{TFA}]\right)$, trihexyl(tetradecyl)phosphonium bistrifluorosulfonylimide $\left[\mathrm{P}_{6,6,6,614}\right]\left[\mathrm{NTf}_{2}\right]$, 1-decyl-3-methylimidazolium bistrifluorosulfonylimide $\left[\mathrm{C}_{10} \mathrm{mim}\right]\left[\mathrm{NTf}_{2}\right]$ were prepared inhouse using standard literature methods from the appropriate organic halide salt. ${ }^{30}$ The halide content of each ionic liquid was measured by using suppressed ion chromatography (IC), ${ }^{31}$ and the characterization of each ionic liquid used is shown in Table 1.

Measurements of the insertion loss and phase were made using transmission measurements on an Agilent E5061 network analyzer with the device clamped in the holder. Deionized water was injected through the cell, and baseline frequencies for insertion loss and velocity change were selected. The viscous

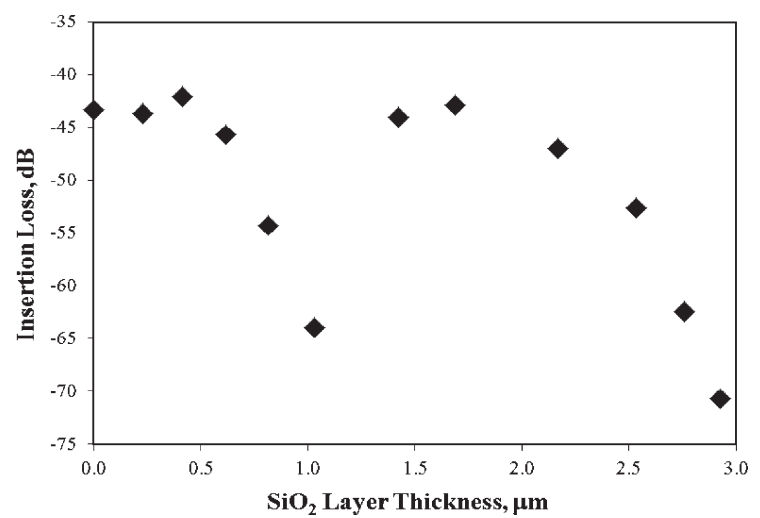

Figure 1. The variation of insertion loss with $\mathrm{SiO}_{2}$ layer thickness.

liquid was then injected, and measurements of relative changes of insertion loss and phase change were made with respect to water at $25{ }^{\circ} \mathrm{C}$. Flow was stopped to collect all spectra. The flow cell was then cleaned by flushing it with $10 \mathrm{~mL}$ of water or until the baseline frequencies were restored.

\section{RESULTS AND DISCUSSION}

To maximize the sensitivity of the Love wave device, the insertion loss in air was measured as the thickness of $\mathrm{SiO}_{2}$ was increased; the results are shown in Figure 1. The two peaks are attributed to the fundamental and first-order guided modes of the $\mathrm{SiO}_{2}$ layer, respectively. ${ }^{14,32,33}$ The device is most sensitive in the regions of greatest change in insertion loss with layer thickness, ${ }^{32}$ which corresponds to the region of $\sim 0.55-0.80 \mu \mathrm{m}$ for the fundamental mode. $\mathrm{A} \mathrm{SiO}_{2}$ thickness of $0.55 \mu \mathrm{m}$ was, therefore, used as a guiding layer for the remainder of the work because this represents the lowest insertion loss within this operating range.

The response of the device with the optimized $\mathrm{SiO}_{2}$ guiding layer thickness to viscous loading was investigated. The variation of the changes in insertion loss and in phase as the square root of the density-viscosity product of the liquid, $(\rho \eta)^{1 / 2}$, was increased are shown in Figure $2 a$ and $b$, respectively. The data for glycerol solutions (up to a concentration of $90 \% \mathrm{v} / \mathrm{v}$ ) show a linear relationship, indicating a Newtonian response, and are consistent with previous experimental work, ${ }^{23,34}$ and thus confirm a good response of the SAW device. The data for the ionic liquids follow the linear relationship up to $(\rho \eta)^{1 / 2} \sim 10 \mathrm{~kg} \mathrm{~m}^{-2} \mathrm{~s}^{-1 / 2}$. Above this value, two of the liquids, $\left(\left[\mathrm{C}_{10} \mathrm{mim}\right]\left[\mathrm{NTf}_{2}\right]\right.$ and $\left.\left[\mathrm{P}_{6,6,6,6,14}\right]\left[\mathrm{NTf}_{2}\right]\right)$, deviate from the linearity. Since both phase and insertion loss changes are measured with respect to water, the lines do not go through the origin, as a zero change in the signals corresponds to the water value of $(\rho \eta)^{1 / 2}=0.99 \mathrm{~kg} \mathrm{~m}^{-2} \mathrm{~s}^{-1 / 2}$. The solid lines in Figure $2 \mathrm{a}$ and $\mathrm{b}$ correspond to the linear best fit of the data taking into account the offset value for water.

A linear relationship between phase and insertion loss given by eq 2 can also be tested to confirm the range of validity of a Newtonian response. Figure 3 clearly shows a linear correlation between the two quantities for the glycerol solutions up to $90 \%$ and for lower viscosity RTILs up to $(\rho \eta)^{1 / 2} \sim 10 \mathrm{~kg} \mathrm{~m}^{-2} \mathrm{~s}^{-1 / 2}$. The best fit to the linear range gives a slope of $6.29 \mathrm{deg} \mathrm{dB}{ }^{-1}$, in excellent agreement with the theoretical value of $6.60 \mathrm{deg} \mathrm{dB}-1$ (eq 2), and thus confirming that glycerol solutions and RTIL liquids up to $10 \mathrm{~kg} \mathrm{~m}^{-2} \mathrm{~s}^{-1 / 2}$ are Newtonian at $\sim 100 \mathrm{MHz}$.

The deviation from the Newtonian linear relationship above $10 \mathrm{~kg} \mathrm{~m}^{-2} \mathrm{~s}^{-1 / 2}$ in Figure 2 increases with increasing $(\rho \eta)^{1 / 2}$. 




Traditionally measured(density $\mathrm{x}$ viscosity) ${ }^{1 / 2}, \mathrm{~kg} \mathrm{~m}^{-2} \mathrm{~s}^{-0.5}$

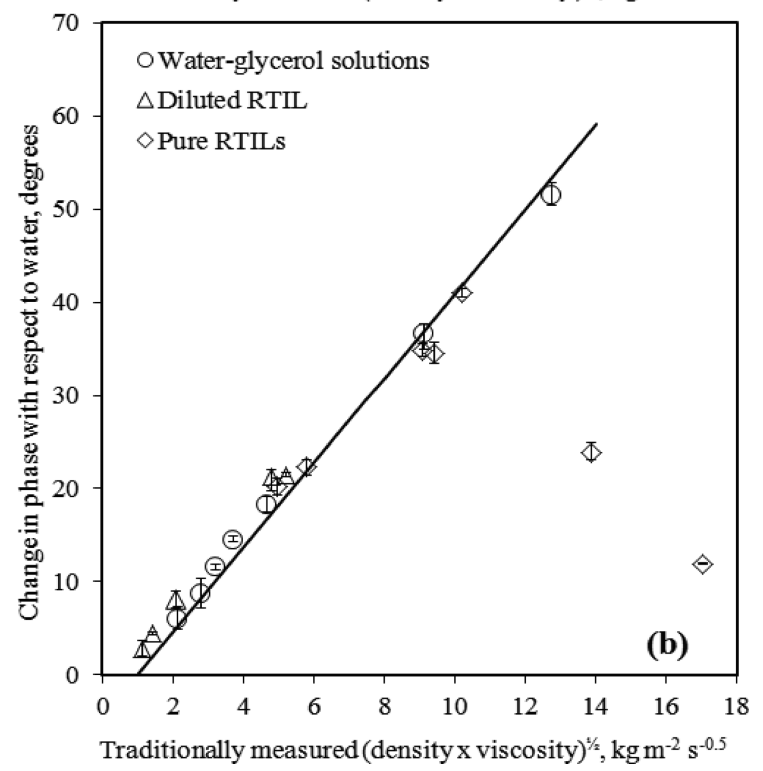

Figure 2. Variation of the changes, with respect to water, in (a) insertion loss and (b) phase with the square root of the density-viscosity product for water- glycerol solutions $(O)$, a diluted RTIL $(\Delta)$, and seven pure RTILs $(\diamond)$. The solid lines are the line of best fit using a density-viscosity value of water of $0.99 \mathrm{~kg} \mathrm{~m}^{-2} \mathrm{~s}^{-1 / 2}$.

The insertion loss appears to saturate (Figure 2a), whereas the phase change decreases strongly with $(\rho \eta)^{1 / 2}$ (Figure $2 \mathrm{~b}$ ), in agreement with theory, and is consistent with a Maxwellian regime when $(\rho \eta)^{1 / 2}$ exceeds $\left(\rho \eta_{\mathrm{c}}\right)^{1 / 2} \cdot{ }^{17,24,34}$ The data are broadly consistent with the QCM measurements at $5 \mathrm{MHz},{ }^{11}$ in which $\left[\mathrm{P}_{6,6,6,14}\right]\left[\mathrm{NTf}_{2}\right]$ was also found to be non-Newtonian. However, $\left[\mathrm{C}_{10} \mathrm{mim}\right]\left[\mathrm{NTf}_{2}\right]$ was found to be Newtonian at QCM frequencies, indicating that $(\rho \eta)^{1 / 2}$ is less than $\left(\rho \eta_{\mathrm{c}}\right)^{1 / 2}$ at 5 $\mathrm{MHz}$ and, since $\left(\rho \eta_{\mathrm{c}}\right)^{1 / 2} \propto \omega^{-1 / 2}$, that $(\rho \eta)^{1 / 2}$ is greater than $\left(\rho \eta_{\mathrm{c}}\right)^{1 / 2}$ at $100 \mathrm{MHz}$. However, at QCM frequencies $\left[\mathrm{C}_{4} \mathrm{mim}\right]$ [TFA], did not lie within the Newtonian range, but in the measurements reported here, it does fit within the linear relationship of eq 2 at SAW frequencies, thus indicating it is Newtonian at both the QCM and SAW frequencies tested. This discrepancy is due to an (incorrect) overestimate of $\rho \eta$ in reference 11 .

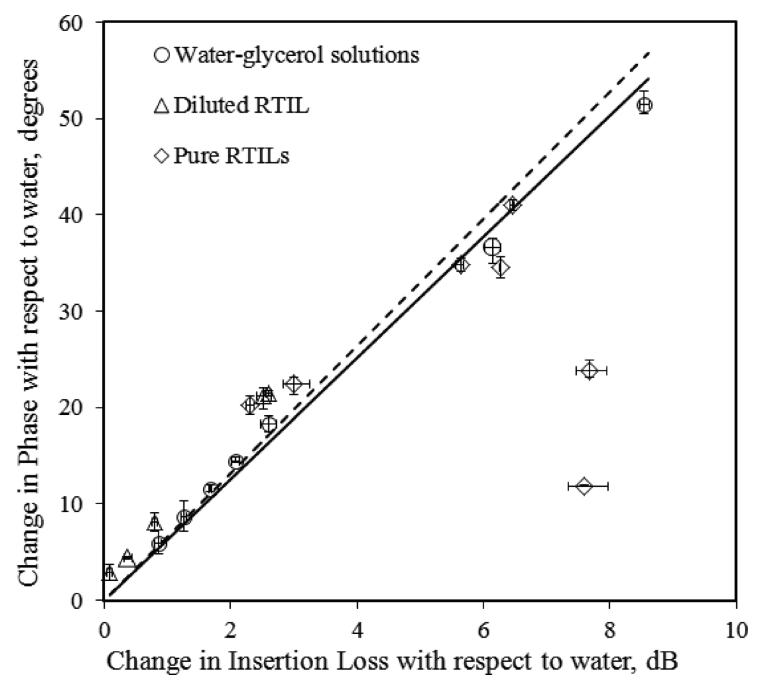

Figure 3. The variation of (with respect to water) phase change against insertion loss changes. The solid line has a slope of $6.29 \mathrm{deg} / \mathrm{dB}$. The dashed line has a slope of $6.60 \mathrm{deg} / \mathrm{dB}$.

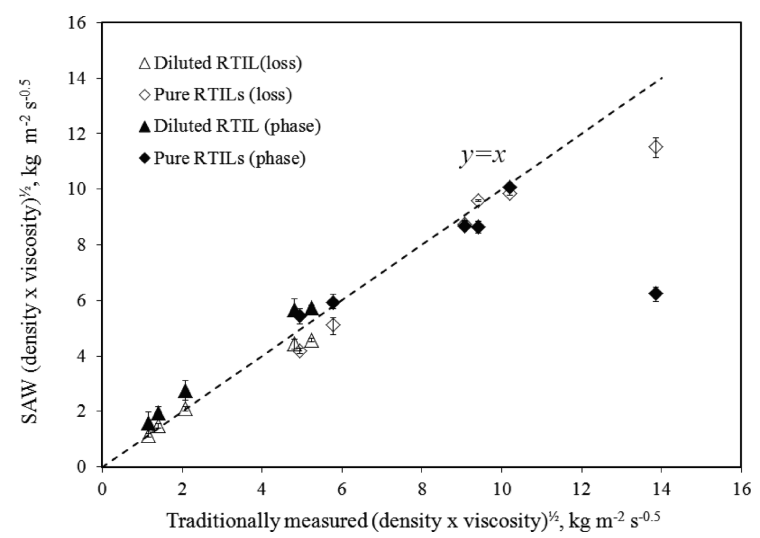

Figure 4. Correlation between the density-viscosity product of diluted and pure RTILS, determined from the changes in insertion loss (empty symbols) and phase change (solid symbols), and those obtained from the viscosity and density meter.

The data can be used to determine the density-viscosity product of a Newtonian RTIL either from phase or insertion loss measurements, provided a calibration liquid is used to determine the constant of proportionality in eq 1 (i.e., effectively the value of $c L_{s} k_{0}$,). In our measurements, glycerol is used as the calibration liquid. The square root density-viscosity is determined from the linear fits in Figure 2a and $b$.

Figure 4 shows the calculated values for square root densityviscosity values against the values measured using the viscosity/ density meter. The dashed line has a slope of unity. A good agreement is observed up to $(\rho \eta)^{1 / 2} \sim 10 \mathrm{~kg} \mathrm{~m}^{-2} \mathrm{~s}^{-1 / 2}$, with an average deviation from the line of $\sim 5 \%$ and $\sim 15 \%$ for loss and phase measurements, respectively. Once the product $\rho \eta$ is determined, the viscosity of the liquid could be determined if its density is known. As discussed in references 11 and 12, it is possible to use the device data in conjunction with predictive modeling of ionic liquid densities to determine the viscosity of a given RTIL. ${ }^{35,36}$ On the basis of the limit of $(\rho \eta)^{1 / 2} \sim 10 \mathrm{~kg}$ $\mathrm{m}^{-2} \mathrm{~s}^{-1 / 2}$ at the chosen Love wave operating frequency of 
$100 \mathrm{MHz}$, we estimate that $\sim 50 \%$ of known RTILs would be accessible to this technique. The percentage accessible could be increased by reducing the operating frequency.

The data can also be used to obtain an estimate of the high frequency shear modulus of the RTILs, $\mu$, by considering the saturation value of the insertion loss with respect to water, shown by the dashed line in Figure 2a, and assuming, in the same way as in reference 15, that all RTILs have the same $\mu$. The glycerol data are again used to determine the constant of proportionality in eq 1 , and eq 3 is used to determine $\rho \mu$. The data indicate values of $\mu \sim(5-6) \times 10^{7} \mathrm{~Pa}$, depending on the RTIL, in very good agreement with the value of $\mu \sim 5.0 \times 10^{7} \mathrm{~Pa}$ obtained for a range of other liquids by Ricco and Martin. ${ }^{15}$ This, in turn, gives a critical value $\left(\rho \eta_{\mathrm{c}}\right)^{1 / 2}=(\rho \mu / \omega)^{1 / 2}$ for the transition to a Maxwellian regime of $(\rho \eta)^{1 / 2} \sim(11.3 \pm 0.5) \mathrm{kg} \mathrm{m}^{-2} \mathrm{~s}^{-1 / 2}$, consistent with our measurements. It should be noted that it would be possible, if more data were available, simultaneously to fit the variations of both phase and insertion loss changes with $(\rho \eta)^{1 / 2}$ over the whole range of $\rho \eta^{17,24}$ and extract a more accurate value of $\left(\rho \eta_{\mathrm{c}}\right)^{1 / 2}$.

\section{CONCLUSION}

We have shown that a Love wave device operating at $100 \mathrm{MHz}$ can be used to determine the density-viscosity product of water miscible and pure Newtonian RTILs if a calibration liquid is used. The changes in phase and insertion loss were found to vary linearly with the square root of the density-viscosity product for values up to $10 \mathrm{~kg} \mathrm{~m}^{-2} \mathrm{~s}^{-1 / 2}$. Above this limit, RTILs were found to have a non-Newtonian response. Although this device has not decreased the sample volume required for characterization compared to a previous measurement using a QCM, it has shown that a Love wave configuration is capable of characterizing room temperature ionic liquids. Significant reduction of the liquid volume required for the Love wave device is possible by minimizing the tubing length and diameter of the flow cell and by reducing the thickness of the O-ring. These results establish the feasibility of incorporating high frequency shear mode acoustic wave devices into microfluidic chips for high throughput measurements of the physical properties of room temperature ionic liquids.

\section{AUTHOR INFORMATION}

\section{Corresponding Author}

*E-mail: fouzia.ouali@ntu.ac.uk.

\section{ACKNOWLEDGMENT}

This work has been supported by the U.K. Engineering \& Physical Sciences Research Council (EPSRC) under Grants EP/ D03826X/1, EP/D038294/1 and EP/D038995/1.

\section{REFERENCES}

(1) Kim, Y. S.; Jang, J. H.; Lim, D. B.; Kang, J. W.; Lee, C. S. Fluid Phase Equilib. 2007, 256, 70-74.

(2) Marsh, K. N.; Boxall, J. A.; Lichtenthaler, R. Fluid Phase Equilib. 2004, 219, 93-98.

(3) Wasserscheid, O.; Welton, T. Ionic Liquids in Synthesis, 2nd ed.; Wiley VCH Verlag: Weinheim, 2008.

(4) de Souza, R. F.; Padilha, J. C.; Gonçalves, R. S.; Dupont, J. Electrochem. Commun. 2003, 5, 728-731.

(5) Binnemans, K. Chem. Rev. 2005, 105, 4148-4204.
(6) Werner, S; Haumann, M; Wasserscheid, P. Ann. Rev. Chem. Biomol. Eng. 2010, 1, 203-230.

(7) Han, X; Armstrong, D. W. Acc. Chem. Res. 2007, 40, 1079-1086.

(8) Kondoh, J.; Saito, K.; Shiokawa, S.; Suzuki, H. Jpn. J. Appl. Phys. 1996, 35, 3093-3096.

(9) Hossenlopp, J. M. Appl. Spectrosc. Rev. 2006, 41, 151-164.

(10) Ballantine, D. S.; White, R. M.; Martin, S. J.; Ricco, A. J.; Zellers, E. T.; Frye, G. C. Wohltjen, H., Acoustic Wave Sensors, Theory, Design and Physico-Chemical Applications; Academic Press: New York, 1997.

(11) McHale, G.; Hardacre, C.; Ge, R.; Doy, N.; Allen, R. W. K.; MacInnes, J. M.; Bown, M. R.; Newton, M. I. Anal. Chem. 2008, $80,5806-5811$.

(12) Doy, N.; McHale, G.; Newton, M. I.; Hardacre, C.; Ge, R.; MacInnes, J. M.; Kuvshinov, D.; Allen, R. W. K. Biomicrofluidics 2010, 4, art. 014107.

(13) Du, J.; Harding, G. L.; Collings, A. F.; Dencher, P. R. Sens. Actuators 1997, A60, 54-61.

(14) McHale, G. Meas. Sci. Technol. 2003, 14, 1847-1853.

(15) Ricco, A. J.; Martin, S. J. Appl. Phys. Lett. 1987, 50, 1474-1476.

(16) Weiss, M.; Welsh, W.; von Schickfus, M.; Hunklinger, S. Anal. Chem. 1998, 70, 2881-2887.

(17) Bandey, H. L.; Martin, S. J.; Cernosek, R. W.; Hillman, A. R. Anal. Chem. 1999, 71, 2205-2214.

(18) Kanazawa, K. K.; Gordon, J. G. Anal. Chim. Acta 1985, $175,99-105$.

(19) McHale, G.; Newton, M. I.; Banerjee, M. K.; Cowen, J. A. Mater. Sci. Eng. 2000, C12, 17-22.

(20) McHale, G; Lücklum, R.; Newton, M. I.; Cowen, J. A. J. Appl. Phys. 2000, 88, 7304-7312.

(21) McHale, G.; Banerjee, M. K.; Newton, M. I.; Krylov, V. V. Phys. Rev B. 1999, 59, 8262-8270.

(22) Josse, F.; Shana, Z. J. Acoust. Soc. Am. 1989, 85, 1556-1559.

(23) Mitsakakis, K.; Tsortos, A.; Kondoh., J.; Gizeli, E. Sens. Actuators 2009, B138, 408-416.

(24) Jackoby, B.; Vellekoop, M. J. Sens. Actuators 1998, A68, 275-281.

(25) Gulyaev, Y. V. IEEE Trans. Ultrason. Ferroelectr. Freq. Control 1998, 45, 935-938.

(26) Gizeli, E.; Stevenson, A. C.; Goddard, N. J.; Lowe, C. R. IEEE Trans. Ultrason. Ferroelectr. Freq. Control 1992, 39, 657-659.

(27) Leonte, J. J.; Shera, G.; Cole, M.; Hesketh, P.; Gardner, J. W. Sens. Actuators 2006, B118, 349-355.

(28) Harding, G.; Du, J. Smart Mater. Struct. 1997, 6, 716-720.

(29) Holbrey, J. D.; Reichert, W. M.; Swatloski, R. P; Broker, G. A.; Pitner, W. R.; Seddon, K. R.; Rogers, R. D. Green Chem. 2002, 4, 407-413.

(30) Bonhôte, P.; Dias, A. P.; Papageorgiou, N.; Kalyanasundram, K.; Grätzel, M. Inorg. Chem. 1996, 5, 1168-1178.

(31) Villagrán, C.; Deetlefs, M.; Pitner, W. R.; Hardacre, C. Anal. Chem. 2004, 76, 2118-2123.

(32) Martin, F.; Newton, M. I.; McHale, G.; Melzak, K. A.; Gizeli, E. Biosens. Bioelectron. 2004, F19, 627-632.

(33) McHale, G.; Newton, M. I.; Martin, F.; Gizeli, E.; Melzak, K. A. Appl. Phys. Lett. 2001, 79, 3542-3543.

(34) Raimbault, V.; Rebiere, D.; Dejous, C.; Guirardel, M.; Conedera, V. Sens. Actuators 2008, A142, 160-165.

(35) Jacquemin, J.; Ge, R.; Nancarrow, P.; Rooney, D. W.; Gomes, M. F. C.; Padua, A. A. H.; Hardacre, C. J. Chem. Eng. Data 2008, $53,716-726$.

(36) Jacquemin, J.; Ge, R.; Nancarrow, P.; Rooney, D. W.; Gomes, M. F. C.; Padua, A. A. H.; Hardacre, C. J. Chem. Eng. Data 2008, 53, 2133-2143. 